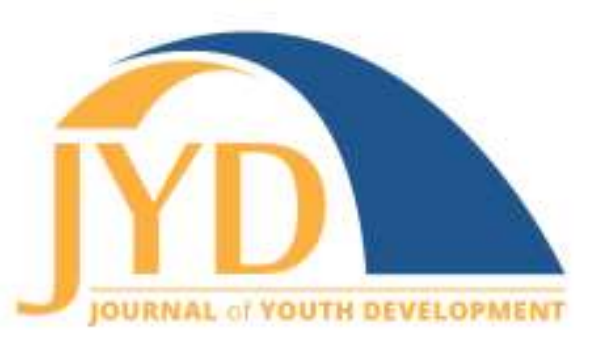

http://jyd.pitt.edu/ | Vol. 12 Issue 1 DOI 10.5195/jyd.2017.501 | ISSN 2325-4017 (online)

\title{
Practitioner Inquiry Matters: Questions by and for Youth Workers
}

\author{
Lindsay Walz \\ Courageous heARTS \\ info@lindsaywalz.com
}

Hayley Tompkins

Minneapolis Beacons/YMCA of the Greater Twin Cities

Hayley.Tompkins@ymcamn.org

\section{Abstract}

The Journal of Youth Development's subtitle is "Bridging Research and Practice, "yet too often our publications reflect a one-way bridge-studies that, at best, have implications for practice. Less represented are practitioner inquiries that rely on practitioner experience and expertise. This special issue aims to bridge the research-practice divide with scholarship produced by youth work practitioners. This article provides a rationale for practitioner inquiry, describes a fellowship effort to support it, and then offers an overview of the ten practitioner inquiries featured in this special issue.

As with many fields, the people who do youth work and the people who think about youth work are frequently not the same. Practitioners and volunteers, researchers and evaluators often constitute distinct groups, both with critical knowledge, both doing essential work. This bifurcation is often more pragmatic than purposeful. In the field of youth development the often underfunded and overstretched workforce is provided very little clearance for the kind of intentional exploration and professional reflection that could benefit the broader field. This special issue aims to bridge the research-practice divide with scholarship produced by youth work practitioners. The articles in this volume illustrate the practice wisdom and reflective inquiry that can occur when youth workers commit to a joint year-long exploration, and carve time from their work day to grapple with the tough questions critical to the field and their own daily work experience.

\footnotetext{
(cc) EY New articles in this journal are licensed under a Creative Commons Attribution 4.0 License. This journal is published by the University Library System, University of Pittsburgh and is cosponsored by the University of Pittsburgh Press. The Journal of Youth Development is the official peer-reviewed publication of the National Association of Extension 4-H Agents and the National AfterSchool Association.
} 
Larson and colleagues (2015) make the case for more research aimed at understanding effective practice from the perspective of practitioners. They urge researchers and practitioners alike to "systematically gather, organize, and make accessible information on practitioners' experience and expertise in ways that can improve training, facilitate practitioner dialogue, and contribute to strengthening the profession" (Larson, Walker, Rusk \& Diaz, 2015. p. 75). Those working in youth-serving organizations are well positioned to identify specific challenges and effective strategies pertinent to their organization (Bialeschki \& Conn, 2011) and to the broader youth development field. This special issue highlighting practitioner inquiry aims to present the nature of the knowledge and expertise thoughtful practitioners bring to the table.

\section{The NorthStar Youth Worker Fellowship}

The articles in this issue are the products of the NorthStar Youth Worker Fellowship, a community-based effort to strengthen youth worker voice and support youth workers in organizational and community leadership roles. It seeks to democratize youth work by inviting and respecting all voices to weigh in on issues of practice, policy and accountability. The NorthStar Youth Worker Fellowship is not a typical professional development class or workshop series guided by a prescribed curriculum to achieve predetermined ends. The fellowship engages a cohort of experienced youth work practitioners in the creative pursuit of action research, exploration, reflection and study in order to generate new wisdom, language, and leadership approaches in the field of youth work.

As a result of this peer-led approach, the fellowship moves toward its goals to (a) unearth and legitimize practice-based perspectives on emergent issues and tensions to broaden current conversations about youth work; (b) support a core group of practitioners in the community dedicated to step up to leadership roles, to speak up with increased confidence, and to represent the field on important policy and practice issues; (c) create a space to incubate practiced theory that influences the field; and (d) demonstrate a commitment to explicit education, training, and professional development for youth workers as essential to high quality practice.

Since 2011, cohorts of mid-career practitioners have come together for a year-long exploration of critical issues in the field and their personal practice. The fellows-experienced, practicing youth workers-formulate an inquiry question and spend the year reviewing relevant research and writings, tapping the local wisdom of their professional network, engaging in conversation 
with local and national leaders in the field, and writing a position paper to inform systems development and field advancement.

Each year the cohort fellows carve out space and time for intentional reflection, research, public presentations and writing about a professional query of their choosing. Yet each year the Fellowship is guided by an overarching theme. Examples include:

- Foundational Theory and Shared Values (2012-13) - Fellows wrestled with questions about essential youth work values, principles and ethics, as well as systems of accountability.

- Issues of Autonomy and Authority (2013-14) - Fellows focused on youth work policy and practice in organizations and communities as well as implications for professional development.

- Rights-based Practice (2014-15) - Motivated by the 25th anniversary of the U. N. Convention on the Rights of the Child, fellows explored how youth work practice could be different, if its purpose honored the promotion and protection of the rights of young people.

- Historic Core Elements Still Relevant Today (2015-16) - Fellows tested core values, key figures and fundamental documents from the past that remain essential to $21^{\text {st }}$ century practice.

To date the fellowship has generated 31 papers that span both historical and present-day challenges and opportunities facing the field. All 31 papers were reviewed and ten were selected for inclusion in this special issue.

\section{Practitioner Inquiries Speak to the Professional Field and to Personal Practice}

The ten practitioner inquiries presented in this volume are divided into two sections. Part one of this special issue explores issues and policies critical to the field of youth development. It focuses on practice and policy dilemmas from a broad field perspective, on big-picture questions about how to advance the field, and on strategies to maintain a quality practice and support youth worker development. Part two contains reflective inquiry into the ethical, moral and relationship challenges of daily practice. These articles are grounded in the unique contexts and practice-based dilemmas that fellows, as experienced youth workers, have faced. Hopefully their perspectives and the insights they have gleaned from their peers will awaken new insights in readers, deepen the influence of practice-based inquiry in the field and encourage the healthy development of youth workers and the young people they serve. 


\section{Part One: Complexities Facing the Field}

Within a United States context, youth work is still a fairly young field, at least by name. It encompasses a wide variety of jobs and engages with a wide variety of young people in an amazing variety of public, private and community spaces. In fact, over the years, many NorthStar fellows have reported not using the term youth worker to describe their occupationsometimes due to the challenge of explaining an often misunderstood profession to the average citizen and other times because they too had not been exposed to the terminology. This very basic experience among youth work professionals raises the question, "How do you identify a field, if the people doing that work struggle to identify with it?" Some might call this dilemma an identity crisis-in fact, many do.

Crisis, in its present understanding, is an experience to be avoided. It connotes danger or difficulty and draws most people's minds to the kind of life-altering events that could lead to ruin. The etymological roots of the word crisis, however, can shift how we interact with and understand the experience of crisis. Its origins come from the Greek word krinein, meaning decide and was commonly used in the early 17 th century to describe a decision point. In using this framework, we can shift away from the negative connotations of crisis to recognize the ways in which the field is at an identity decision point. From where we're sitting, it's an experience to be relished not avoided.

Developmentally, the field is trying to find itself in the same way many young people are. We try on different ideas, sometimes conforming to look like the "cool kids" and other times proclaiming our uniqueness with a veracity that might be off-putting to the "adults" in the room. As youth workers, we understand the importance of this tension in the lives of young people and provide opportunities for youth to "thrash out their reactions, consider the pluses and minuses, and try to determine where they themselves stand so that they will be better able to deal with ideas of all shades" (Konopka, 1973, p. 302).

Just as we are willing to sit in this tension with young people -being who we are and discovering who they are-we must be willing to sit with this tension in the field, this identity decision point. We cannot simply conform to our predecessors' ways of being today knowing they will not serve the uniqueness of this field, nor can we completely reject labels and boxes from the past. Instead, we must thrash out our reactions to determine where we, ourselves stand. We must lift up our formational values, ethics, and principles so that our decision points 
are rooted in and guided by this collective sense of self. Practitioner inquiry supports this foundational process of digging deeply into the ethics and knowledge of self, context, others. The five articles in the first section of this volume attempt to do just that. Despite the diverse ways in which youth work is practiced by these authors, they have lifted up fundamental aspects of their experience and practice that can guide the field toward its truest identity. It involves embracing complexities and seeing uncertainties as opportunities to learn while involving people young and old.

Deena Zubulake takes us into the values, principles, and ethics of youth work through her perspective of engaging our most vulnerable young people. She highlights the need for a profession built on a common philosophical approach.

Angel Peluso takes the reader into her lived experience as a program supervisor trying to promote quality under the constraints of a largely volunteer and entry-level staff. Her awareness about the importance of relationship-building, reflection and connection are elevated through practical changes to her approach and physical environment.

Jocelyn Wiedow and Shaina Abraham both highlight reflection as a critical means of supporting quality youth work practice. Jocelyn offers keen insight into the importance of authentic reflective supervision practices, identifying the key benefits and addressing common barriers. Her article is essential reading for youth worker supervisors. Shaina focuses on peer-supported reflection through a Reflection Circle process. She challenges organizations and intermediaries to create space for shared wisdom and professional development that crosses typical employer boundaries to develop learning communities for youth workers.

Finally, Kari Denissen Cunnien offers a counter argument to credentialing, encouraging us to embrace the complexities of the field and invest in the creation of a system that supports the development of youth work professionals through responsive learning opportunities and healthy organizational practices.

As these practitioners elevate their voices, the proclamation, "Nothing about us, without us is for us" echoes beneath their words. As we move through this identity decision-point, we must create space for those who do the work to influence how it is done. 


\section{Part Two: The Challenges of Daily Practice}

In this section, we capture youth worker inquiry where the rubber meets the road. These narratives are personal. They present the voices of individual youth workers attempting to uncover a new understanding of a complex issue or question. These articles not only include useful research, they also paint portraits of a youth worker's experience, process, community, and belief systems. The portraits illustrate the many ways that youth workers learn about and understand their work. While each story and reflection is unique, they do share some common themes.

First, they reveal similar ways of knowing and learning. These youth workers learn from their communities, asking young people, other youth workers, families, and colleagues as they examine complex issues. They explore the historical context of policies and their communities to establish a greater understanding of today.

Second, they ask lots of questions and are tenacious about seeking answers. They examine intentionality, asking important and challenging questions of themselves, other youth workers, schools, and systems: Are you doing what you want to do? Are you doing what you think you are? Are you doing what you should do? How do you know? They explore practice and policy to make sense of how and why youth workers, programs, and systems approach their work intentionally.

Third, they confront and explore issues of equity both inside and outside their programs. They ask: What work do we do with whom? And why? We must ask the essential questions about how individual programs, agencies, and systems create and support programs for young people. They explore program design, school systems, accountability, and how youth workers can provide quality, effective programs for young people even if it doesn't align with an agency's priorities. They ask: Who is accountable to whom?

The five articles in this section offer portraits that include thoughtful and complex explorations of some of our field's biggest challenges.

Jennifer Lindwall is a youth worker asking a terribly difficult policy question that has implications for practice. Should organizations assign mentors to young people without regard to race and 
ethnicity? She examines the role and risks of white supremacy and whiteness in the field of mentoring youth from marginalized communities.

Chris Ochoki is a therapist reflecting upon how the schools both serve and under-serve Latino students in a rural community. His inquiry explores the role of parents in affairs of the school and asks, to what degree does a school intentionally treat newcomers differently?

Angela Bonfiglio is a youth worker asking the most essential questions about how her identity and role as a faith-based youth worker can impact and/or support young people in a turbulent and frightening time. Do you continue your youth program as usual when your young people live in a community fully focused on racial outrage and inequity?

Emily Scribner-O'Pray is a public-sector youth worker examining the history and merit of evidence based interventions for young people and youth workers. She shares her concerns for implementation and effectiveness when balancing practical youth concerns about sexual and reproductive health with policy prescribed boundaries determined by policymakers with no connections to the community.

Monica McDaniel is a youth worker and social work student using history and personal reflection to explore three types of youth development theory. Is good youth development work social justice work? Is it good prevention work? Is it good individual personal development work?

These youth workers highlight the importance of intentionality both in practice and policy, providing thoughtful research and insight to the complex challenges of our field. We must continue to focus on equity through intentional practice, thoughtful policy, authentic partnership, and constant reflective inquiry.

\section{Conclusion}

Each of these practitioner inquiries opens up questions for the practitioner, the field and the researcher. Each inquiry and each practitioner is different, but underlying the search for answers are driving concerns that are both personal and professional, and both ethical and practical. Instead of answers, more questions arise, and with new questions, the deliberations among the fellows get more lively. Conversations circle around to the beginning: What is the meaning of this work? What are our duties and responsibilities to the young people with whom we work? What does it mean to commit to rights-based youth work? What does equity in youth 
work look like? How do I keep young people front and center of the work I do? How do I step away from doing to and for young people and instead joining and working with them? To whom am I accountable? How do I contribute to the development of my colleagues?

Reading, researching, reflecting, debating, sharing stories and writing about one's work brings a clarity that allows one to take a stance and speak publicly about important issues. It prepares a youth worker to sit at the table with teachers, funders, evaluators, policymakers, young people and parents to begin to sort through and potentially solve some of the issues that impact the lives of our youth today. Initiatives that inspire inquiry and promote voice contribute powerfully to personal and professional development and the future of the field.

\section{References}

Bialeschki, M. D., \& Conn, M. (2011). Welcome to our world: Bridging youth development research in nonprofit and academic communities. Journal of Research on Adolescence, 21(1), 300-306.

Konopka, G. (1973). Requirements for healthy development of adolescent youth. Adolescence, $8(31), 291-316$.

Larson, R., Walker, K., Rusk, N., \& Diaz, L.B. (2015). Understanding youth development from the practitioner's point of view: A call for research on effective practice. Applied Developmental Science, 19(2), 74-86. 